\title{
Impacto da Implantação e Desenvolvimento do Grupo de Tumor de Mama e sua Contribuição à Assistência, à Pesquisa e ao Ensino no Instituto Nacional de Câncer José Alencar Gomes da Silva
} Impact of the Implementation and Development of the Breast Tumor Group and its Contribution to Care, Research and Teaching at the Brazilian National Cancer Institute José Alencar Gomes da Silva

Impacto de la Implantación y Desarrollo del Grupo de Tumor de Mama y su Contribución a la Asistencia, a la Investigación y a la Enseñanza en el Instituto Nacional del Cáncer José Alencar Gomes da Silva

Márcia Marília Vargas Fróes Skaba ${ }^{1}$; Rildo Pereira da Silva ${ }^{2}$; Carlos Henrique Debenedito Silva ${ }^{3}$; Joecy Dias de Andrade ${ }^{4}$ Maria da Glória dos Santos Nunes $^{5}$; Antonio Tadeu Cheriff dos Santos ${ }^{6}$; Maria de Fátima Batalha de Menezes ${ }^{7}$; Pedro Luiz Fernandes ${ }^{8}$; Romeu Gomes ${ }^{9}$; Teresa Caldas Camargo ${ }^{10}$

\section{Resumo}

Introduçáo: Os Grupos de Tumores foram implantados no Instituto Nacional de Câncer José Alencar Gomes da Silva a partir da proposta conjunta com a British Columbia Cancer Agency. Tal proposta prevê o uso de equipes multidisciplinares para promover a cooperação e a colaboração entre os setores da atenção à saúde e as áreas de desenvolvimento de pesquisa. O Grupo de Tumores de Mama constituiu-se na primeira experiência sob essa nova forma de pensar e agir na condução e na gestáo do problema do câncer, desenvolvendo suas atividades desde março de 2009. Objetivo: Avaliar a implantação do Grupo de Tumores de Mama, seu desenvolvimento e contribuição à assistência, à pesquisa e ao ensino. Método: Estudo descritivo qualitativo pautado no método "Hermenêutico-Dialético", mediante grupos focais e entrevistas abertas e semiestruturadas realizadas entre fevereiro e abril de 2012. Resultados: O modelo de organização e operacionalização do Grupo de Tumores de Mama mostrou-se adequado, inclusive para a abordagem de outros cânceres, uma vez que se revelou em uma experiência exitosa de perspectiva multidisciplinar, espaço de decisóes coletivas, compartilhamento de saberes e práticas, bem como de exemplo de gestáo contextualizada na realidade brasileira. Entretanto, os depoimentos indicaram a necessidade de reconhecimento da formalizaçáo do grupo, assim como a criação de estratégias para a articulação eficiente dos processos de assistência, ensino e pesquisa. Conclusão: Para que o modelo de organização dos grupos de tumores se dissemine e consolide, faz-se necessária sua efetiva formalização na estrutura institucional, assim como a real integração entre assistência, ensino e pesquisa.

Palavras-chave: Avaliação em Saúde; Saúde da Mulher; Neoplasias da Mama; Prevenção \& controle; Pesquisa Qualitativa

Resumo de pesquisa realizada pelo Núcleo de Pesquisa e Estudos Qualitativos (NUPEQuali/INCA), com o apoio da Organizaçấo Pan-Americana da Saúde, por meio do Contrato de Serviços BR/CNT/1101332.001.

${ }^{1}$ Doutora em Ciências. Núcleo de Pesquisa e Estudos Qualitativos do Instituto Nacional de Câncer José Alencar Gomes da Silva (NUPEQuali/INCA).

${ }^{2}$ Doutorando em Epistemologia e História da Ciência. NUPEQuali/INCA.

${ }^{3}$ Mestre em Tocoginecologia. Hospital do Câncer IV/INCA. NUPEQuali/INCA.

${ }^{4}$ Mestre em Tecnologia Educacional nas Ciências da Saúde. NUPEQuali/INCA.

${ }^{5}$ Mestre em Enfermagem. Hospital do Câncer I/INCA. NUPEQuali/INCA.

${ }^{6}$ Doutor em Filosofia. NUPEQuali/INCA.

${ }^{7}$ Doutora em Enfermagem. Hospital do Câncer I/INCA. Coordenaçấo de Educação/ INCA. NUPEQuali/INCA.

${ }^{8}$ Doutor em Ciência da Informação. Hospital do Câncer IV/INCA. NUPEQuali/INCA.

${ }^{9}$ Doutor em Saúde Pública. Pós-graduação em Saúde da Criança e da Mulher/IFF/Fiocruz.

${ }^{10}$ Doutora em Enfermagem. Coordenaçấo-Geral de Prevenção e Vigilância do INCA. NUPEQuali/INCA.

Endereço para correspondência: Márcia Marília Vargas Fróes Skaba. Rua Marques de Pombal, 125 - 7 o andar - Centro. Rio de Janeiro (RJ), Brasil.

E-mail: marciaskaba@inca.gov.br. 


\section{INTRODUÇÃO}

No Brasil, as estimativas de câncer para o ano de 2012, válidas também para o ano de 2013, apontam a ocorrência de aproximadamente 518.510 casos novos, sendo esta a terceira causa de morte na população brasileira, precedido apenas pelas doenças cardiovasculares e pelas causas externas ${ }^{1}$. Entre os diversos tipos de neoplasia, o câncer de mama tem uma forte expressão na saúde pública brasileira, sendo responsável por inúmeras mortes de mulheres no Brasil. Para 2012, estima-se a ocorrência de 52.680 novos casos de câncer de mama feminina no Brasil ${ }^{1}$.

Esse grave problema de saúde pública é expresso por sua alta incidência, morbidade, mortalidade e elevado custo no tratamento. O aumento da mortalidade por câncer de mama se constitui num desafio para a gestão em saúde, tanto no que se refere à elaboração e ao desenvolvimento de políticas que promovam a redução da mortalidade quanto à tomada de conhecimento das tendências e reconhecimento das dificuldades enfrentadas em toda a linha do cuidado, por parte dos gestores.

Portanto, além da perspectiva epidemiológica, não se pode deixar de sublinhar a complexidade dessa doença no que tange aos diferentes aspectos que a sua abordagem impóe. Dessa forma, faz-se imprescindível discutir o câncer de mama por meio de uma perspectiva multidisciplinar.

Neste sentido, o Grupo de Tumores (GT) é um modelo que se propóe a substituir a organização corrente, baseada numa estrutura departamental que tende a compartimentar os processos de assistência, pesquisa e gestão das políticas públicas.

Esse modelo visa a favorecer a elaboração de ações que de fato proporcionem impacto na atenção dos usuários em todo o seu itinerário terapêutico. Estratégias desse tipo estão sendo desenvolvidas em algumas províncias do Canadá, envolvendo gestores e profissionais da área de saúde.

Assim, a ideia da implantaçấo dos Grupos de Tumores no Instituto Nacional de Câncer José Alencar Gomes da Silva (INCA) ocorreu a partir da proposta conjunta com a British Columbia Cancer Agency, que tomou forma a partir do 3rd International Cancer Care Congress, realizado em 2007, na Cidade do Rio de Janeiro.

Tal proposta, basicamente, salientava a noção do uso de equipes multidisciplinares para promover a cooperação e a colaboração entre os setores da atenção à saúde e às áreas de desenvolvimento de pesquisa nas instituiçôes. Desse modo, o Grupo de Tumores de Mama (GTM) constituiu-se na primeira experiência sob essa nova forma de pensar e agir na condução e na gestão do problema do câncer de mama, desenvolvendo suas atividades desde março de 2009.
Este estudo teve como objetivo avaliar a implantação do GTM, seu desenvolvimento e sua contribuição à assistência, à pesquisa e ao ensino no INCA. Espera-se com essa avaliação subsidiar não só o monitoramento do referido grupo, como também a criação de grupos voltados para outros cânceres.

\section{MÉTODO}

Trata-se de um estudo descritivo qualitativo que, essencialmente, visou à apreensão de significados no sentido de refletir a totalidade em suas múltiplas dimensôes ${ }^{2}$. Sem a pretensão de ter domínio total, nem tampouco construir leis gerais quantificáveis, buscou-se construir um caminho de aproximaçóes para a compreensão da realidade estudada.

Em cumprimento da Resolução 196/96 do Conselho Nacional de Saúde, a pesquisa foi desenvolvida após a aprovação do Comitê de Ética em Pesquisa (CEP) do INCA sob o número 144/2011.

A pesquisa ocorreu em três etapas: elaboração da imagem-objetivo; construção de indicadores qualitativos e avaliação da implantação.

A primeira constitui-se da elaboração da imagem-objetivo, envolvendo o acesso a dois conjuntos de fontes. O primeiro diz respeito aos documentos relacionados aos antecedentes e à própria criação do grupo. Já o segundo se refere às entrevistas com informantes que participaram da criação do mencionado grupo. Os critérios de inclusão dos sujeitos para essa etapa foram determinados da seguinte forma: ter sido membro do 3rd International Cancer Care Congress, realizado em 2007, na Cidade do Rio de Janeiro; e participado da visita ao British Columbia Cancer Agency, no Canadá.

Tanto na análise documental quanto nas entrevistas com informantes, procurou-se obter informaçóes voltadas para o esquema do Quadro 1.

A segunda etapa tratou da construção de indicadores qualitativos, aqui entendidos como aqueles que "expressam a voz, os sentimentos, os pensamentos e as práticas dos diversos atores que compóem o universo de uma pesquisa ou de uma avaliação"”. Essa construção foi realizada por meio da técnica de Grupo Focal (GF) 2,4,5.

A inclusão dos sujeitos nessa etapa obedeceu aos seguintes critérios: ser membro do GTM e indicado pelo Coordenador; com participação mínima de um ano no grupo. Como critério de exclusão foi estipulado ser membro com participação esporádica ou convidado eventual nas reunióes.

A dinâmica do GF permitiu o estabelecimento das discussóes com vistas a formular e obter consenso dos indicadores qualitativos associados à imagem-objetivo. 
Com base nessa discussão, o moderador estimulou o grupo a buscar um consenso mínimo para a montagem do Quadro 2.

Quadro 1. Imagem-objetivo do GTM

\begin{tabular}{|l|l|l|l|}
\hline \multicolumn{3}{|c|}{ Imagem-objetivo do GTM } \\
\hline \multicolumn{1}{|c|}{ Aspecto } & $\begin{array}{c}\text { Segundo os } \\
\text { documentos }\end{array}$ & $\begin{array}{c}\text { Na ótica } \\
\text { dos } \\
\text { informantes }\end{array}$ & Síntese \\
\hline $\begin{array}{l}\text { Definição do } \\
\text { GTM }\end{array}$ & & & \\
\hline $\begin{array}{l}\text { Objetivos do } \\
\text { GTM }\end{array}$ & & & \\
\hline $\begin{array}{l}\text { Justificativa } \\
\text { ou } \\
\text { antecedentes } \\
\text { que levaram } \\
\text { à criação do } \\
\text { GTM }\end{array}$ & & & \\
\hline $\begin{array}{l}\text { Estratégias } \\
\text { do GTM } \\
\text { para que } \\
\text { se possam } \\
\text { alcançar } \\
\text { os seus } \\
\text { objetivos }\end{array}$ & & & \\
\hline
\end{tabular}

Quadro 2. Indicadores qualitativos

\begin{tabular}{|c|c|c|}
\hline $\begin{array}{c}\text { Objetivo } \\
\text { GTM }\end{array}$ & $\begin{array}{c}\text { Indicador } \\
\text { de } \\
\text { avaliação }\end{array}$ & $\begin{array}{c}\text { Descritor (definição } \\
\text { do indicador) }\end{array}$ \\
\hline
\end{tabular}

A terceira etapa consistiu na efetiva avaliação da implantação do GTM, o que ocorreu por meio da realização de entrevistas semiestruturadas com os profissionais que atuavam nesse grupo. A técnica - entendida como uma conversa dirigida por perguntas abertas - pautou-se em um desenho de amostra qualitativa ${ }^{6}$. Essa amostra foi delineada de modo que o número de entrevistados fosse suficiente para se atingir a saturação dos sentidos, prevendo a possibilidade de haver inclusóes de sujeitos até que fosse possível uma discussão ampla das questóes de pesquisa. A inclusão dos sujeitos obedeceu aos mesmos critérios da etapa anterior.

As transcriçóes das gravaçōes das entrevistas foram analisadas a partir do método de interpretação de sentido $^{7,2}$, baseando-se em princípios hermenêutico-dialéticos, traduzidos na dialética "pergunta-resposta" e na interação com os resultados encontrados de modo a "fundir horizontes" relativos às questôes de estudo e àquelas obtidas na investigação realizada. A interação entre esses dois horizontes possibilitou a construção de um novo discurso ao interpretar o discurso que examina ${ }^{6}$, compreendendo o contexto, as razóes e as lógicas de falas, açōes e inter-relaçōes entre grupos e instituiçōes ${ }^{7,2}$.

Para manter o anonimato dos participantes do estudo, os fragmentos das falas foram referenciados com a abreviatura E, de entrevistado, seguida de numeração arábica.

A trajetória analítico-interpretativa envolveu os seguintes passos: (a) leitura compreensiva do material; (b) identificação dos sentidos subjacentes às falas dos sujeitos; (c) problematização das ideias e dos sentidos presentes nos depoimentos; (d) articulação com significados socioculturais; e (e) elaboração de síntese entre os dados empíricos, informaçôes provenientes de outros estudos acerca do assunto e o referencial teórico do estudo.

\section{RESULTADOS E DISCUSSÃO}

A imagem-objetivo foi elaborada a partir dos depoimentos coletados nas entrevistas com os formuladores da proposta inicial do GTM e da análise documental (1a etapa da pesquisa), considerando a compreensão expressa acerca das práticas dos diversos sujeitos participantes, tendo como foco os objetivos do grupo. O Quadro 3 indica os resultados encontrados.

Após a construção da imagem-objetivo, foi desenvolvido o processo de validação da mesma e a construçáo dos indicadores qualitativos ( $2^{\mathrm{a}}$ etapa da pesquisa), por meio da realização do GF3. O Quadro 4 apresenta os indicadores obtidos após a validação da imagem-objetivo pelo GF.

$\mathrm{Na}$ terceira etapa, obedecendo a composição da imagem-objetivo e dos indicadores qualitativos, seguiram-se entrevistas abertas com os participantes do GTM. Essas entrevistas visaram a esclarecer o objetivo da pesquisa, que permitiu a elaboração do roteiro da entrevista. Após a análise dos depoimentos, foi possível destacar as seguintes categorias: Sentidos; Propósitos; Facilidades e Dificuldades da Implantação e do Desenvolvimento; Desafios para o GTM no âmbito do INCA.

\section{SentIDOS ATRIBUÍDOS AO GTM}

Para os sujeitos da pesquisa, o grupo assume diferentes sentidos, aqui entendidos como uma apropriação de significados culturalmente estabelecidos por meio da experimentação e das interações situadas na cultura e no processo interacional histórico ${ }^{8}$. Entre os sentidos mais recorrentemente atribuídos, destaca-se a multidisciplinaridade.

[...] muitos interlocutores, de diversas áreas, tem essa questão da multidisciplinaridade que eu acho que é uma coisa super-rica. (E02) 
Quadro 3. Imagem-objetivo do GTM/INCA

\begin{tabular}{|c|c|c|}
\hline Aspecto & Segundo os documentos & Na ótica dos informantes \\
\hline $\begin{array}{l}\text { Definição do } \\
\text { GTM }\end{array}$ & $\begin{array}{l}\text { É um grupo de caráter multidisciplinar que } \\
\text { colabora no controle do câncer de mama, em } \\
\text { fluxo contínuo } \\
\text { É um grupo de caráter multi-institucional }\end{array}$ & $\begin{array}{l}\text { É um grupo que reúne profissionais de } \\
\text { diferentes áreas de especialidades para } \\
\text { abordar o câncer de mama a partir de } \\
\text { uma perspectiva multiprofissional }\end{array}$ \\
\hline $\begin{array}{l}\text { Objetivos do } \\
\text { GTM }\end{array}$ & $\begin{array}{l}\text { Ser referência para o câncer de mama } \\
\text { na instituição, sendo ator no processo de } \\
\text { identificação de problemas e busca/sugestões } \\
\text { de soluções }\end{array}$ & $\begin{array}{l}\text { Promover o controle do câncer de mama } \\
\text { Mudar o modelo técnico-científico para } \\
\text { abordar o câncer de mama } \\
\text { Transformar uma nova dimensão } \\
\text { conceitual em formas de organização } \\
\text { institucionais (quebra ou rearranjo das } \\
\text { caixinhas) e dos processos de trabalho } \\
\text { para abordar o câncer de mama }\end{array}$ \\
\hline $\begin{array}{l}\text { Justificativa ou } \\
\text { antecedentes } \\
\text { que levaram } \\
\text { à criação do } \\
\text { GTM }\end{array}$ & $\begin{array}{l}\text { Em 2007, estabeleceu-se a relação entre o } \\
\text { British Columbia Cancer Agency (Vancouver) e } \\
\text { o INCA, durante o } 3^{\circ} \text { Congresso Internacional } \\
\text { sobre Cuidados em Câncer } \\
\text { Em novembro de 2008, uma missão do INCA } \\
\text { visitou a Agência (Vancouver) para conhecer } \\
\text { a abordagem de base populacional para o } \\
\text { controle do câncer a as estratégias usadas pelos } \\
\text { líderes do BCCA } \\
\text { Firmado o Convênio de colaboração entre os } \\
\text { ministérios do Canadá e do Brasil } \\
\text { De janeiro a março de 2009, Dr. Sutcliffe } \\
\text { (representante de British Columbia) visitou o } \\
\text { INCA com vistas à formalização do convênio } \\
\text { Foi identificada a necessidade do INCA superar } \\
\text { dois grandes desafios: desenvolver técnica } \\
\text { e cientificamente o Instituto e ampliar sua } \\
\text { liderança nacional } \\
\text { Início do GTM (abril de 2009) } \\
\text { Em novembro de } 2009 \text {, o INCA recebe uma } \\
\text { delegação do BCCA }\end{array}$ & $\begin{array}{l}\text { O grupo foi pensado e criado para } \\
\text { lidar com a lógica da especialização na } \\
\text { abordagem do câncer que, de um lado, } \\
\text { possibilita um maior aprofundamento e, } \\
\text { de outro, pode delimitar a abordagem } \\
\text { Nesse sentido, surgiu como uma } \\
\text { estratégia a ser incorporada na } \\
\text { organização tradicional acerca dessa } \\
\text { doença }\end{array}$ \\
\hline $\begin{array}{l}\text { Estratégias } \\
\text { do GTM para } \\
\text { que se possam } \\
\text { alcançar os } \\
\text { seus objetivos }\end{array}$ & $\begin{array}{l}\text { Agregar outras instituições que possam } \\
\text { colaborar na melhoria do controle do câncer de } \\
\text { mama } \\
\text { Abordar o desfecho, diagnóstico, e tratamento, } \\
\text { bem como a estrutura quanto aos recursos } \\
\text { humanos, equipamentos e insumos necessários } \\
\text { Analisar a operacionalização das ações e das } \\
\text { atividades na atenção ao câncer de mama } \\
\text { Escolher através de votação entre os membros } \\
\text { do GTM, o líder do grupo } \\
\text { Implementar um canal na intranet para } \\
\text { divulgação do GTM } \\
\text { Criar planilhas para determinação de } \\
\text { prioridades de ações em câncer de mama de } \\
\text { cada área } \\
\text { Propor um evento em novembro de } 2009 \text { para } \\
\text { fechamento das propostas dos grupos }\end{array}$ & $\begin{array}{l}\text { Articular a pesquisa básica com a } \\
\text { pesquisa clínica } \\
\text { Promover consensos } \\
\text { Fornecer subsídios para a elaboração de } \\
\text { recomendações para o planejamento, a } \\
\text { prevenção e a intervenção }\end{array}$ \\
\hline
\end{tabular}

Fonte: Documentos relacionados ao GTM e entrevistas semiestruturadas 
Quadro 4. Indicadores qualitativos

\begin{tabular}{|c|c|c|}
\hline Objetivos & Indicadores & Descritores \\
\hline $\begin{array}{l}\text { 1. Promover o } \\
\text { controle do câncer } \\
\text { de mama }\end{array}$ & $\begin{array}{l}\text { 1. Informações sobre as pacientes } \\
\text { 2. Problemas relacionados ao fluxo e ao } \\
\text { acesso }\end{array}$ & $\begin{array}{l}\text { 1. Organização das informações sobre a } \\
\text { história clínica, fluxo e acesso } \\
\text { 2. Identificação de problemas } \\
\text { relacionados ao fluxo, rastreamento e ao } \\
\text { acesso }\end{array}$ \\
\hline $\begin{array}{l}\text { 2. Implementar o } \\
\text { modelo técnico- } \\
\text {-científico para } \\
\text { abordar o câncer } \\
\text { de mama }\end{array}$ & $\begin{array}{l}\text { 1. Linhas de pesquisa do INCA } \\
\text { 2. Percentual de pacientes incluídos em } \\
\text { ensaios clínicos } \\
\text { 3. Percentual da sobrevida no primeiro ano } \\
\text { de tratamento }\end{array}$ & $\begin{array}{l}\text { 1. Estabelecimento de linhas de pesquisa } \\
\text { relacionadas à história natural da } \\
\text { doença, medicina baseada em evidência, } \\
\text { sobrevida e satisfação da cliente } \\
\text { 2. Aumento da inclusão de pacientes em } \\
\text { ensaios clínicos } \\
\text { 3. Sobrevida no primeiro ano de } \\
\text { tratamento }\end{array}$ \\
\hline $\begin{array}{l}\text { 3. Transformar } \\
\text { uma nova } \\
\text { dimensão } \\
\text { conceitual em } \\
\text { formas de } \\
\text { organização } \\
\text { institucional } \\
\text { (articulação entre } \\
\text { Serviços) e dos } \\
\text { processos de } \\
\text { trabalho para } \\
\text { abordar o câncer } \\
\text { de mama }\end{array}$ & $\begin{array}{l}\text { 2. Atendimento integrado } \\
\text { 3. Discussões/decisões tomadas com a } \\
\text { participação da Rede }\end{array}$ & $\begin{array}{l}\text { 2. Evidências de articulação entre os } \\
\text { Serviços do INCA } \\
\text { 3. Participação da Rede nas discussões }\end{array}$ \\
\hline
\end{tabular}

Fonte: Documentos, Entrevistas e Grupo Focal

A multidisciplinaridade pode ser uma etapa para a interdisciplinaridade. Levando em conta essas consideraçóes, pode-se dizer que - segundo a ótica dos entrevistados - o grupo que se configura como multidisciplinar almeja ser interdisciplinar?

Outro sentido recorrente nos depoimentos é o que percebe o grupo como um espaço em que assistência e pesquisa se articulam.

[Deve] não só produzir açôes assistenciais, como açôes de produção de conhecimentos mais integradas. (E07)

Essa articulação, mencionada pelos sujeitos, pode ser fruto da motivaçáo de se construir procedimentos oncológicos voltados para o câncer de mama, baseados em estudos clínicos validados, buscando a diminuição das incertezas no processo clínico (diagnóstico/terapêutica/ prognóstico) por meio de consulta contínua das informaçôes validadas em pesquisas de epidemiologia clínica; as incertezas ainda rondam os processos clínicos frente às complexidades e perplexidades da condiçáo humana ${ }^{10}$.
Um terceiro sentido atribuído é o de grupo não formalizado.

Ele não é um órgão, ele [...] nem consta do organograma da Instituição. (E05)

Nesse sentido, observa-se que - embora tenha legitimidade institucional - o GTM ainda não foi formalmente instituído. Com base no conceito de modelo institucional, pode-se considerar, a partir de algumas entrevistas, que o grupo ainda não alcançou características formais dentro das quais ele seja legalmente concebido, com contornos jurídicos que permitem o cumprimento de suas funçôes ${ }^{11}$.

A associação do GTM ao modelo de British Columbia (Canadá) também permeia um dos sentidos atribuídos a esse grupo.

A gente fez uma versão brasileira do modelo [British Columbia]. (E04)

Essa associação - de certa forma - é atravessada por uma ambivalência vivenciada a partir da coexistência de 
ordens conflitivas, o que não é necessariamente destrutiva, uma vez que pode servir como um estímulo para que as pessoas formulem projetos e evitem escolhas irreversíveis e decisões inequívocas ${ }^{12}$.

Nesse sentido, a partir da experiência de British Columbia, tanto pode se formular um novo modelo, tomando como referência as especificidades estruturais de seu contexto, quanto pode se integrar as diferenças em uma unidade para se lidar com o câncer de mama.

Por último, destacam-se os sentidos atribuídos ao grupo como espaço de aprendizagem e prazer.

[É] uma oportunidade ímpar pra eu desenvolver melhor o meu conhecimento sobre o câncer de mama [...], discutir e propor coisas novas. (E08)

Em síntese, a percepção que se tem do GTM se caracteriza por uma polissemia constituída por diferentes sentidos que - ao invés de serem contraditórios - se agregam, mesmo expressando diferentes dimensôes.

\section{PROPÓSITOS DO GTM}

Enquanto propósitos idealizados e realizados, os sujeitos de pesquisa o indicam como um espaço em que assistência e pesquisa se estruturam em torno de uma nova instância e/ou ensejo reorganizador voltado para a questão da prevenção e controle do câncer.

Promover estudos a respeito do tema, estudos com cunho multiprofissional que possam trazer [...] benefícios para a assistência, controle do câncer de mama de forma geral. (E10)

Foi da compreensão desses processos que emergiu a incorporação do conceito de modelo técnico-científico como se vê a seguir:

[...] tem essa promoção desse conceito. De técnico-científico no sentido de uma maior integraçáo, ter a parte científica com a parte técnica assistencial, eu acho que isso é quase um desdobramento disso, acho que esse seria o subitem do objetivo principal. (E09)

O GTM também é apontado como um propulsor para uma redefinição de fluxos que integre assistência e pesquisa na Instituição e na Rede.

[...] elencou-se uma série de problemas que eram importantes [...] problemas, [de] fluxo, se trouxe pessoal do município para dizer como que era o fluxo até a chegada ao INCA [...] houve várias mudanças. Reescreveram todas as rotinas, as rotinas foram discutidas ponto a ponto nas reuniōes do GT. (E03)
A discussão e a otimização da organização desses fluxos são, dessa forma, um elemento fundamental a ser mantido e ampliado no sentido de uma efetiva organização que integre a assistência e a pesquisa.

[...] o GTM já tem contribuído na medida em que expóe isso [fluxo dos serviços] e traz os profissionais pra discutir e identificar as dificuldades do fluxo. (E05)

Essa ação se relaciona com uma preocupação e meta do grupo voltada para uma efetiva redução da mortalidade e melhoria dos desfechos clínicos.

[O] Grupo de Tumor tem como objetivo principal mudar mortalidade pelo câncer de mama. Esse é o objetivo número um do Grupo de Tumor. (E01)

Já como propósitos idealizados e não realizados, a implantação do grupo é tida como uma experiência ainda em construção, estando a organização dos seus processos de trabalho sujeita a aprimoramentos. Isso estaria relacionado ao aspecto da definição formal das suas atribuiçóes e do seu lugar na Instituição.

Os propósitos náo idealizados e realizados surgiram pela articulaçâo dos diversos segmentos institucionais, na revisão das rotinas internas e na participação no Outubro Rosa. Este último é considerado um dos grandes marcos da atuação do GTM.

A própria organização do Outubro Rosa nos outros anos e nesse ano, [...] a meu ver, isso é um produto do Grupo de Tumor. (E09)

Esse evento - recorrentemente mencionado - tanto pode ser entendido como marco temporal para a reconstituição de enredos das experiências vivenciadas pelos sujeitos e pelo grupo, quanto simbolicamente servir de síntese identitária do que se deseja ${ }^{13}$.

Portanto, o grupo tem a consciência de que esse novo modelo ganha força legitimadora enquanto uma ação multiprofissional, oriunda justamente, da participação dos vários profissionais. Nesse sentido, é um espaço de troca, gratificação e reconhecimento das açóes desses profissionais no INCA.

\section{FACILIDADES E DIFICULDADES DA IMPLANTAÇÃO E DO DESENVOLVIMENTO DO GTM}

As facilidades associadas à implantação do grupo partem do seu próprio ato fundador, uma vez que surge enquanto uma ideia dos membros da gestáo executiva do INCA, legando para o grupo um elemento de força e prestígio institucional. 
O Grupo foi lançado com todo o prestígio da Instituição [...] uma aposta que esse tipo de modelo, de reunir o corpo técnico-científico, podia funcionar. (E04)

Uma facilidade para o seu desenvolvimento se deve a liderança exercida pelo coordenador junto ao grupo. Ele foi reconhecido de modo unânime pelos seus integrantes:

[...] liderança agregadora, muito educado, ele é politicamente correto [...] eu acho que ajudou tremendamente. Encontrar outra pessoa com as qualidades que ele tem aqui dentro seria difícil. (E06)

Esse perfil de liderança possibilitou o fortalecimento do trabalho, pois oportunizou o desenvolvimento do grupo por meio de habilidades pessoais que incluem influência no contexto organizacional, capacidade de comunicação e cooperaçáo, convergindo para o gerenciamento das relaçôes, além de inspirar as pessoas para o alcance de metas coletivas ${ }^{14}$.

O trabalho colaborativo foi mais um elemento apontado como facilitador para o seu desenvolvimento, o qual recebeu ainda o reforço das reunióes frequentes no HCIII - a unidade do INCA especializada no tratamento do câncer de mama e entendida como locus privilegiado para as discussóes - uma vez que congregou os profissionais que lidam com diagnóstico, tratamento, ensino e pesquisa relacionados ao câncer de mama no Instituto:

[...] tem discussóes e divergências de opiniáo, mas o grupo está muito comprometido com o trabalho, com as propostas [...]. (E05)

O Grupo de Tumor tem uma característica distinta [...] por estar instalado numa unidade em que toda atividade é ligada a câncer de mama. É diferente da cabeça e pescoço. (E09)

Náo foram relatadas dificuldades no contexto da implantação. No entanto, há referências a fatos que indicam dificuldades para o desenvolvimento do trabalho do grupo. Uma delas refere-se ao não acompanhamento permanente das reunióes e discussóes pela alta gestão, conforme a fala a seguir:

Eu acho que a direção fez o que ela deveria ter feito no início. O que eu lamento é que [...] devido às crises institucionais, infelizmente mais de uma, a atençáo dos gestores foi concentrada, desviada para lidar com incêndios eventuais [...] os próprios gestores são transparentes que seu tempo e atenção têm que ser direcionados ao que é essencial para a sobrevida da Instituição. (E04)
Uma dificuldade que aparece de modo recorrente relacionada ao seu desenvolvimento trata da indefiniçáo do seu papel. Tal indicativo está em consonância com o terceiro sentido atribuído ao de grupo não formalizado expresso no relato a seguir:

[...] não há uma formatação muito clara [na estrutura do GTM] [...] tem alguns aspectos que ainda estão fluidos, qual é o papel, qual é a ação real e prática, onde estão os limites, onde estão as fronteiras [...] não está muito claro isso na Instituição. (E09)

Também os depoentes foram enfáticos ao referir que o modelo no qual o GTM foi inspirado náo se adequa a nossa realidade, principalmente no que se refere às características da população atendida para o diagnóstico e o tratamento do câncer de mama (estadiamento da doença) e os recursos sociais disponíveis para a clientela.

[...] o modelo foi um modelo baseado no British Columbia, a gente não é o British Columbia, entendeu? A gente tem pacientes com outro estádio, com outras questôes sociais muito graves, às vezes, o paciente não volta porque náo tem dinheiro pra passagem [...] não da pra querer que a gente seja um British Columbia. Então eu acho que tem que pegar agora os Grupos e adequar à nossa realidade e ver o que a gente precisa. (E02)

Outro entrave refere-se ao sistema de informação do INCA, que ainda apresenta desafios ligados à integração das informaçóes produzidas nas diversas áreas do Instituto.

[...] vários sistemas de informação dentro do INCA, muitos deles coletam a mesma informação, ou pelo menos tem o mesmo objetivo [precisa ocorrer uma unificação dos sistemas de informação]. (E08)

Os demais elementos, apontados como problemas a serem sanados para melhorar o desenvolvimento das atividades, são relacionados a uma política de recursos humanos e de um pensamento estratégico que dê conta da integraçáo dos processos de ensino articulados ao modelo do grupo.

[...] principais entraves [...] são para pesquisa [...] inclusão de paciente [...] e uma enfermeira de pesquisa ou mais de uma [...] a CEDC [Coordenação de Educação] tinha que investir em formação [...] o segundo entrave realmente é a Patologia. (E02)

\section{DESAFIOS PARA O GTM NO ÂMBITO DO INCA}

Um dos desafios destacados foi a articulação entre ensino-pesquisa-assistência na Mastologia, sendo que o maior deles é integrar o ensino-aprendizagem às práticas relacionadas à assistência. 
[...] um programa onde conseguisse incluir os residentes que vão fazer suas monografias nas áreas específicas [...] na verdade isso é um multiplicador [...] [existência de] linhas de projetos [...] aprovados pelo GTM [...] e a CEDC tinha que investir na formação. (E02)

Outro desafio é o de compartilhar os saberes das diversas áreas profissionais, no sentido de dosar a relação estratégica entre o ensino, a prática e a pesquisa. Ensinar exige pesquisa [...] não há ensino sem pesquisa e pesquisa sem ensino. A indagação, a busca, a pesquisa faz parte da natureza da prática assistencial, isto é o insumo do saber fazer. Compartilhar conhecimento e saberes exige criatividade [...] demanda estética e ética no processo de ensino-aprendizagem ${ }^{15}$.

O desafio relacionado ao aumento da mortalidade por câncer de mama, com as suas importantes variaçôes regionais, está em como a equipe de saúde e gestores envolvidos irão elaborar e desenvolver políticas que promovam a redução dessa mortalidade ${ }^{16,17}$.

A redução da mortalidade por câncer também foi mencionada, ainda que genericamente.

"[...] [pesquisa como] movimento de atualizaçáo [...] troca de informaçóes [...] ação cooperativa interna [...] produçáo de conhecimento [...] [que] tenha quantidade e qualidade [...] produzir em diferentes eixos temáticos do controle do câncer de mama [...] [na] assistência e na prevençáo [...] [fazer] o melhor possível dentro da força de trabalho e capacidade operacional que a Instituição tem”. (E07)

Em síntese, o elenco dos desafios apontado pelos entrevistados reflete não só as açóes internas ao grupo, mas remetem a questôes que não se esgotam no próprio.

\section{CONCLUSÃO}

O GTM mostrou-se como um modelo adequado para a abordagem de outros tipos de câncer, uma vez que se revelou uma experiência exitosa de perspectiva multidisciplinar, espaço de decisões coletivas, compartilhamento de saberes e práticas, bem como de exemplo de gestáo contextualizada na realidade brasileira. Entretanto, para que essa estratégia se desenvolva, faz-se necessária a sua efetiva formalização na estrutura institucional, bem como um maior investimento para a real articulação entre ensino, pesquisa e assistência. Igualmente, faz-se necessário observar que o alcance desses objetivos se traduz em açóes contínuas e não delimitadas temporalmente.

\section{CONTRIBUIÇÕES}

Todos os autores participaram da concepção e planejamento da pesquisa; obtenção, análise e interpretação dos dados; e redaçáo do artigo.

\section{Declaraçáo de Conflito de Interesses: Nada a Declarar.}

\section{REFERÊNCIAS}

1. Instituto Nacional de Câncer José Alencar Gomes da Silva. Estimativa 2012: incidência de câncer no Brasil. Rio de Janeiro: INCA; 2011. 118 p.

2. Minayo MCS, Deslandes SF, Gomes R. Pesquisa Social: teoria, método e criatividade. Rio de Janeiro:Vozes;2007.

3. Minayo MCS. Construção de indicadores qualitativos para avaliação de mudanças. Revista Brasileira de Educação Médica 2009; 33 supl. 1: 83-91.

4. Pereira EB. A liderança na enfermagem em oncologia e os nexos com a humanização: uma perspectiva dos líderes. [dissertação]. Rio de Janeiro: Universidade Federal do Rio de Janeiro, Escola de Enfermagem Anna Nery; 2007.

5. Ruediger MA, Riccio V. Grupo focal: método e análise simbólica da organização. Rio de Janeiro: FGV; 2004.

6. Minayo MCS. O desafio do conhecimento: pesquisa qualitativa em saúde. São Paulo: Hucitec; 2006.

7. Gomes R, Souza ER, Minayo MCS, et al. Organização, processamento, análise e interpretação de dados: o desafio da triangulação. In: Minayo MCS, Assis SG, Souza ER, organizadoras. Avaliação por triangulação de métodos: abordagem de programas sociais. Rio de Janeiro: Fiocruz; 2005. p. 185-221.

8. Berger PL, Luckman T. A construção social da realidade. Petrópolis: Vozes; 2001.

9. Gusdorf G. Prefácio. In: Japiassu H. Interdisciplinaridade e patologia do saber. Rio de Janeiro: Imago; 1976.

10. Castiel LD, Póvoa EC. Dr. Sackett \& "Mr. Sacketeer”... Encanto e desencanto no reino da expertise na medicina baseada em evidências. Cad Saude Publica 2001;17(1):205-14.

11. Garcia AEB, Salles Filho SLM. Trajetória institucional de um instituto público de pesquisa: o caso do Ital após 1995. Revista de Administração Pública 2009; 43(3):661-93.

12. Berrebi-Hoffman I, Lallement M, Nicole-Drancourt C, Sarfati F. Ambivalência, gênero e modernidade capitalista: a França na era da flexibilidade. Cadernos Pagu 2009; 32: $9-42$.

13. Good BJ. Medicine, Rationality and Experience: An Anthropological Perspective. Cambridge: Cambridge University Press; 1994.

14. Motta PR. Gestão contemporânea: a ciência e a arte de ser dirigente. 13. ed. Rio de Janeiro: Record; 2002.

15. Freire P. Ensinar exige pesquisa. In: __. Pedagogia da autonomia: saberes necessários à prática educativa. 25 . ed. São Paulo: Paz e Terra; 1996. 
16. Wunsch-Filho V, Moncau JE. Mortalidade por câncer no Brasil 1980-1995: padrōes regionais e tendências temporais. Rev Assoc Med Bras 2002; 48(3):250-7.
17. Fonseca LAM, Eluf-Neto J, Wunsch-Filho V.Tendências da mortalidade por câncer nas capitais dos estados do Brasil, 1980-2004. Rev Assoc Med Bras 2010;56(3):309-12. 


\begin{abstract}
Introduction: Tumor Groups were deployed at the Brazilian National Cancer Institute José Alencar Gomes da Silva from the joint proposal with British Columbia Cancer Agency. Such Proposal provides for the use of multidisciplinary teams to promote cooperation and collaboration among health care sector and research development areas. The Breast Tumors Group is the first experience of this new way of thinking and acting on the conduction and management of the cancer problem, having conducted its activities since March 2009. Objective: To evaluate the Breast Tumors Group deployment, development and contribution to care, research and teaching. Method: Descriptive and qualitative study based on the "Hermeneutic-dialectic" method, by focal groups and open and semi-structured interviews, done between February and April 2012. Results: The Breast Tumors Group's organization and operation method was shown to be suitable, even to approach other types of cancer, since it revealed itself as a successful experience of: multidisciplinary experience, collective decision space; sharing of practices and knowledge; as well as an example of management contextualized within Brazilian reality. However, testimonies showed the need of the acknowledgement of the group's formalization, as well as the creation of strategies for efficient articulation of caring, teaching and research processes. Conclusion: For the Tumor Groups model of organization to spread and consolidate, it is necessary its effective formalization in the institutional framework, as well as the actual integration between care, teaching and research Key words: Health Evaluation; Women's Health; Breast Neoplasms; Prevention \& control; Qualitative Research
\end{abstract}

\title{
Resumen
}

Introducción: Los Grupos de Tumores han sido implantados en el Instituto Nacional del Cáncer José Alencar Gomes da Silva a partir de la propuesta conjunta con la British Columbia Cancer Agency. Tal propuesta prevé la utilización de equipos multidisciplinarios para promocionar la cooperación y la colaboración entre los sectores de la atención a la salud y áreas de desarrollo de investigación. El Grupo de Tumores de Mama se ha constituido en la primera experiencia bajo esa nueva manera de pensar y actuar en la conducción y en la gestión del problema del cáncer, desarrollando sus actividades desde marzo de 2009. Objetivo: Evaluar la implantación del Grupo de Tumores de Mama, su desarrollo y contribución a la asistencia, a la investigación y a la enseńanza. Método: Estudio descriptivo cualitativo basado en la metodología "Hermenéutico-Dialéctico", a través de grupos focales y entrevistas abiertas y semi-estructuradas, realizadas entre febrero y abril de 2012. Resultados: El modelo de organización y actuación del Grupo de Tumores de Mama se ha mostrado adecuado, inclusive para el abordaje de otros cánceres, una vez que se ha revelado en una experiencia exitosa de: perspectiva multidisciplinar; espacio de decisiones colectivas; compartir el saber y las prácticas; así como de ejemplo de gestión contextualizada en la realidad brasileńa. Entretanto, las declaraciones indicaron la necesidad de reconocimiento de la formalización del grupo, así como la creación de estrategias para la articulación eficaz de los procesos de asistencia, enseñanza e investigación. Conclusión: Para que el modelo de organización de los grupos de tumores se disemine y consolide, haz se necesaria su efectiva formalización en la estructura institucional, así como la real integración entre asistencia, enseñanza e investigación.

Palabras clave: Evaluación en Salud; Salud de la Mujer; Neoplasias de la Mama; Prevención \& control; Investigación Cualitativa 